\title{
Our Italian Experience Using Lung Ultrasound for Identification, Grading and Serial Follow-up of Severity of Lung Involvement for Management of Patients with COVID-19
}

Luigi Vetrugno ${ }^{1}$, Tiziana Bove ${ }^{1}$, Daniele Orso ${ }^{1}$, Federico Barbariol $^{2}$, Flavio Bassi ${ }^{2}$, Enrico Boero $^{3}$, Giovanni Ferrari ${ }^{4}$, Robert Kong ${ }^{5}$, and Daniel A. Lichtenstein ${ }^{6}$

${ }^{1}$ Department of Medicine, University of Udine, Italy

${ }^{2}$ University-Hospital of Udine, Italy

${ }^{3}$ Anesthesia and Intensive Care, San Giovanni Bosco Hospital, Torino, Italy ${ }^{4}$ SC Pneumologia ad Indirizzo Semi Intensivo, Azienda Ospedaliera Ordine Mauriziano ${ }^{5}$ Cardiac Anaesthesia \& Intensive Care, Brighton \& Sussex University Hospital, Brighton BN2 5BE United Kingdom ${ }^{6}$ Medical Intensive Care Unit, Hospital Ambroise Paré (AP-HP), Paris-West university, 9 avenue Charles de Gaulle, F-92100, Boulogne (Paris-West), France.

May 5, 2020

\begin{abstract}
Lung ultrasound (LU) has rapidly become a tool for assessment of patients stricken by the novel coronavirus 2019 (COVID19). Over the past two and a half months (January, February and first half of March 2020) we have used this modality for identification of lung involvement along with pulmonary severity in patients with suspected or documented COVID-19 infection. Use of LU has helped us in clinical decision making and reduced the use of both chest x-rays and computed tomography (CT).
\end{abstract}

Published in Echocardiography. DOI forthcoming.

\section{Authors' contributions}

LV and DO concept, design and drafting the manuscript. TB, FB, EB, FB, GF critical revision of the manuscript for important intellectual content. RK and DL critical review and editing the manuscript. All authors read and approved the final manuscript.

\section{Lung ultrasound}

During this ongoing battle against the novel COVID-19, LU has quickly been recognized as a tool for diagnosis and monitoring of lung involvement severity (1).

A normal LU demonstrates what are termed A lines. These are a repetition of the pleural line at the same distance from skin to the pleural line. This is indicative of air below the pleural line, corresponding to the 
parietal pleura. Lines may be complete or partial (Figure 1, Movie 1).

Demonstration of B lines are described as hyperechoic laser-like artifacts that resemble a "comet tail" (Figure 2 ). These arise from the pleural line and move in concert with a sliding lung. The A lines are generally not present. B1 lines are associated with an interstitial syndrome and diminished lung aeration. B2 lines are confluent lines appearing as a "white lung" (called also glass-rockets), equivalent to computed tomography (CT) ground-glass opacities. This suggests a more severe loss of lung aeration (Movies 2 and 3).

Lung consolidations (C) are associated with hepatization of lung parenchyma with or without air bronchograms, and suggest major loss of lung aeration (atelectasis vs. pneumonia) (Movie 4).

We have not identified an ultrasound appearance that would be pathognomonic of COVID-19 (4).

\section{Lung ultrasound score}

The lung ultrasound score (LUS) has been shown to be a useful tool in intensive care (ICU) patients with adult respiratory distress syndrome (ARDS). We feel this has been of value in assessing severity of lung involvement with COVID-19 (2-3).

One may perform a topographic analysis of the underlying lung regions daily without moving the patient. A scan of the three different areas of the thorax: anterior, lateral, and posterior, and then superior and inferior segments are performed. Thus, six specific regions for each lung are defined and categorized by one of four different aeration patterns.

A point scoring system is employed by region and ultrasound pattern as: $\mathrm{A}=0$ point, $\mathrm{B} 1=1$ point, $\mathrm{B} 2=$ 2 points, $\mathrm{C}=3$ points. Thus, a LUS of 0 is normal, and 36 would be the worst.

LUS score can be used to follow the clinical patient trajectory in which an increased score means decreased lung aeration, while on the contrary, a decrease in score means an increase in lung aeration limiting the need of chest x-ray and CT scan (4).

An experienced sonographer can do this examination within 5 minutes, while brief training and about 25 supervised exams seem to be sufficient to achieve a basic ability to perform the study (5). A prior study showed the impact of LU to affect clinical decisions in up to $50 \%$ of intensive care unit patients (6).

\section{Clinical context}

Although a patient's clinical context allows for an improved pre-test estimate of COVID-19 lung involvement, it appears that LU may serve as a bedside tool to improve evaluation of lung involvement, and also reduce the use of chest x-rays and CT (7). In addition, several intensive care units following central venous line positioning with ultrasound, have not been routinely obtaining post insertion chest x-rays (8-9).

While the ability of a chest $\mathrm{x}$-ray to discriminate a bacterial pneumonia from a non-bacterial infection is no more than $60 \%$ (10), LU has a higher sensitivity (80\%) (11). Specific comparison studies in critically ill patients regarding viral pneumonia, however, are few (12).

\section{Conclusion}

During this pandemic we have used LU in patients suspected or diagnosed with COVID-19. Application of LUS has allowed for identification of patients with lung involvement and severity. In addition, serial studies help us follow for progression or regression of disease. 
With the application of LU we have had a noted reduction in use of chest x-rays and CT scans during this pandemic, helping make care and management of our patients a little more efficient.

\section{REFERENCES}

1. Peng QY, Wang XT, Zhang LN, Chinese Critical Care Ultrasound Study Group (CCUSG). Finding of lung ultrasonography of novel coronavirus pneumonia during the 2019-2020 epidemic. Intensive Care Med 2020 Mar 12. doi: 10.1007/s00134-020-05996-6.

2. Man MA, Dantes E, Domokos Hancu B, Bondor CI, Ruscovan A, Parau A, Motoc NS, Marc M. Correlation between transthoracic lung ultrasound score and HRCT features in patients with interstitial lung diseases. J Clin Med 2019; 8 (8). pii: E1199. doi: 10.3390/jcm8081199.

3. Zhao Z, Jiang L, Xi X, Jiang Q, Zhu B, Wang M, Xing J, Zhang D. Prognostic value of extravascular lung water assessed with lung ultrasound score by chest sonography in patients with acute respiratory distress syndrome. BMC Pulm Med. 2015;15: 98. doi: 10.1186/s12890-015-0091-2.

4. Bouhemad B, Mongodi S, Via Gabriele, Rouquette I. Ultrasound for "Lung Monitoring" of ventilation patients. Anesthesiology 2015;122: 437-47. doi: 10.1097/ALN.0000000000000558.

5. Rouby JJ, Arbelot C, Gao Y, et al. Training for Lung Ultrasound Score Measurement in Critically Ill Patients. Am J Respir Crit Care Med 2018. [Epub ahead of print].

6. Xirouchaki N, Kondili E, Prinianakis G, et al. Impact of lung ultrasound on clinical decision making in critically ill patients. Intensive Care Med 2014;40:57-65.

7. Brogi E, Bignami E, Sidoti A, Shawae M, Gargani L, Vetrugno L, et al. Could the use of bedside lung ultrasound reduce the number of chest x-rays in the intensive care unit? Cardiovasc Ultrasound 2017; 15:23. doi: 10.1186/s12947-017-0113-8.

8. Smit JM, Haaksma ME, Lim EHT, Steenvoorden TS, Blans MJ, Bosch. FH et al. Ultrasound to detect central venous catheter placement associated complications: a multicenter diagnostic accuracy study. Anesthesiology 2020; 132:781-94. Doi: 10.1097/ALN.0000000000003126.

9. Vetrugno L, Bove T, Orso D, Flabio B, Boero E, Ferrari G. Lung ultrasound and COVID-19 "pattern": not all that glitters today is gold tomorrow. J Ultrasound in Med. (Accepted for publication)

10. Courtoy I, Lande AE, Turner RB. Accuracy of radiographic differentiation of bacterial from nonbacterial pneumonia. Clin Pediatr (Phila) 1989; 28(6): 261-264.

11. Berce V, Tomazin M, Gorenjak M, Berce T, Lovrenčič B. The usefulness of lung ultrasound for the aetiological diagnosis of community-acquired pneumonia in children. Sci Rep 2019; 9(1): 17957.

12. Testa A, Soldati G, Copetti R, Giannuzzi R, Portale G, Gentiloni Silveri N. Early recognition of the 2009 pandemic influenza A (H1N1) pneumonia by chest ultrasound. Crit Care 2012; 16(1): R30. 


\section{Figures}

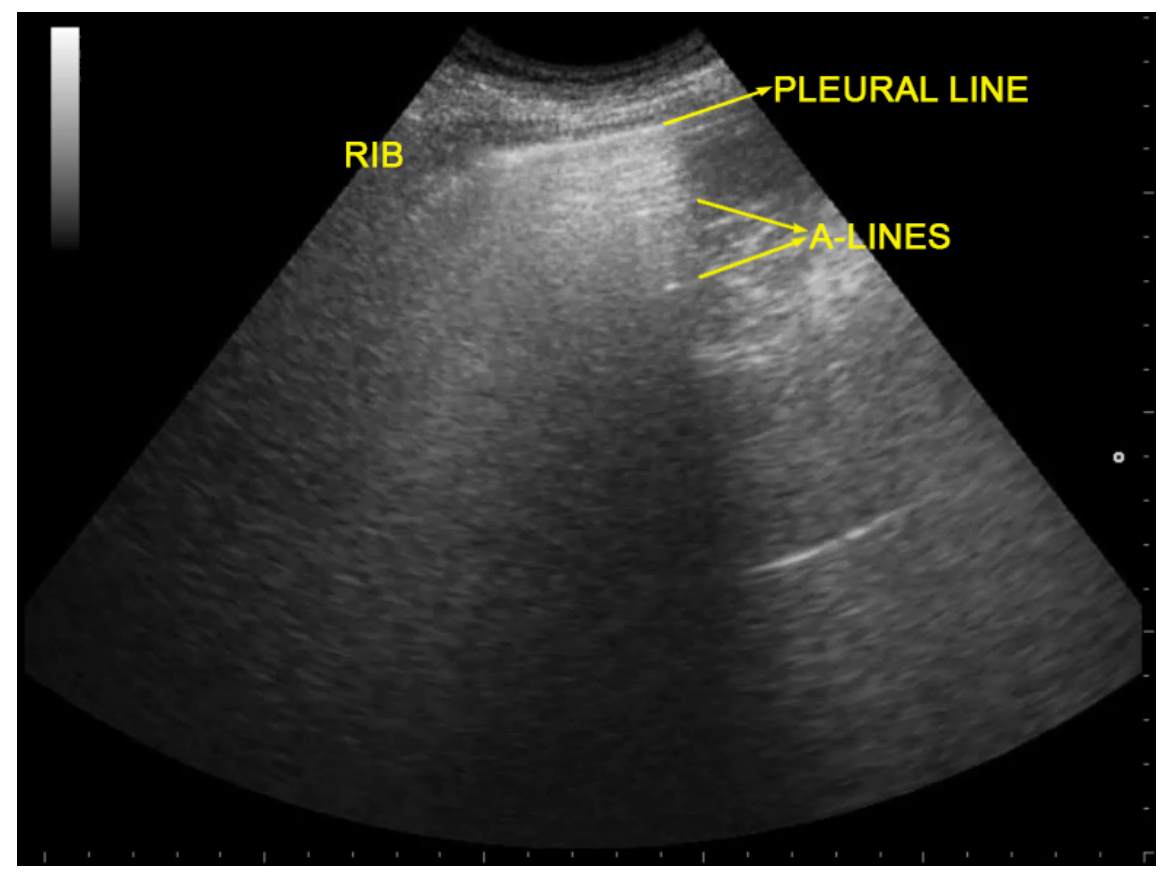

Figure 1: Lung ultrasound of normal aerated lung. A lines are visible: they are a repetition of the pleural line at the same distance from skin to pleural line. This indicates the presence of air below the pleural line (which corresponds to the parietal pleura). A lines can be complete or partial (as in this image); 


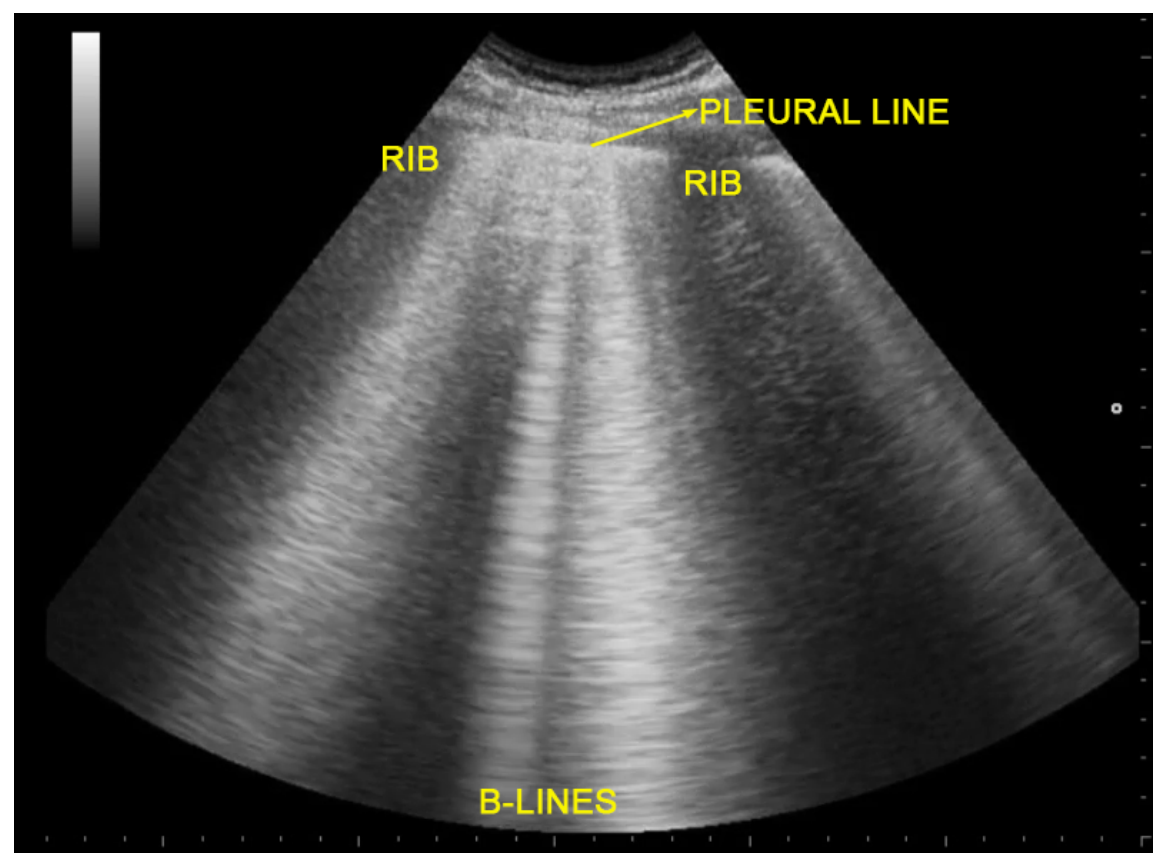

Figure 2: Lung ultrasound of interstitial syndrome, characterized by the presence of three or more B lines between two ribs. B lines are hyperechoic laser-like artifacts that resemble a comet tail, arise from the pleural line and move in concert with lung sliding. A lines are wiped out.

\section{Supplemental information}

Movie1: Anterior region with A lines.

\section{Hosted file}

1-movie.avi available at https://authorea.com/users/5588/articles/438105-our-italianexperience-using-lung-ultrasound-for-identification-grading-and-serial-follow-up-ofseverity-of-lung-involvement-for-management-of-patients-with-covid-19

Movie 2: Posterior region with coalescent B lines.

\section{Hosted file}

2-movie.avi available at https://authorea.com/users/5588/articles/438105-our-italianexperience-using-lung-ultrasound-for-identification-grading-and-serial-follow-up-ofseverity-of-lung-involvement-for-management-of-patients-with-covid-19

Movie 3: A thickened and disrupted pleural line with B lines.

\section{Hosted file}

3-movie.avi available at https://authorea.com/users/5588/articles/438105-our-italianexperience-using-lung-ultrasound-for-identification-grading-and-serial-follow-up-ofseverity-of-lung-involvement-for-management-of-patients-with-covid-19 
Movie 4: A subpleural consolidation disappearing with inspiration.

\section{Hosted file}

4-movie.avi available at https://authorea.com/users/5588/articles/438105-our-italianexperience-using-lung-ultrasound-for-identification-grading-and-serial-follow-up-ofseverity-of-lung-involvement-for-management-of-patients-with-covid-19 